\title{
Research Paper \\ The Professional Development Program for Teaching Teachers Based on Evidence-Based Practices for Students with Autism Spectrum Disorders: A Systematic Review Study
}

\author{
Gholamali Afrooz $^{1}$, Abbas Ali Taghipour Javan ${ }^{* 2}$, Saeed Hasanzade ${ }^{3}$, Masoud Gholamali Lavasani ${ }^{4}$
}

1. Professor, Department of Psychology of Exceptional Children, Faculty of Psychology, University of Tehran, Iran

2. Ph.D. Student of Psychology of Exceptional Children, Faculty of Psychology and Educational Sciences, University of Tehran, Iran

3. Associate Professor, Department of Psychology of Exceptional Children, Faculty of Psychology and Educational Sciences, University of Tehran, Iran

4. Associate Professor, Department of Psychology and Educational Psychology and Counseling, University of Tehran, Iran

Citation: Afrooz G, Taghipour Javan AA, Hasanzade S, Gholamali Lavasani M. The Professional Development Program for Teaching Teachers Based on Evidence-Based Practices for Students with Autism Spectrum Disorders: A Systematic Review Study. J Child Ment Health. 2021; 8 (1):43-60.

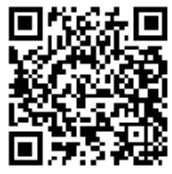

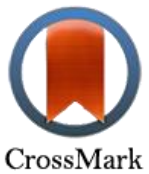

$\underline{10.52547 / \mathrm{jcmh} .8 .1 .5}$

URL: http://childmentalhealth.ir/article-1-855-en.html

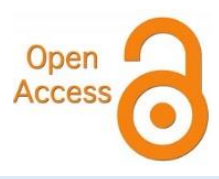

\section{A R T I C L E I N F O}

Keywords:

Professional

development, evidence-based practices, students with autism spectrum disorders, systematic review

Received: 4 Jul 2019 Accepted: 19 Sep 20219 Available: 29 May 2021

\section{A B S T R A C T}

Background and Purpose: Autism spectrum disorder (ASD) is a lifelong developmental condition that is characterized by specific problems in social interaction and communication, the ability to think and flexible behavior, and perception and managing of sensory stimuli. Due to the presence of students with autism in public education schools, it is necessary to develop the teaching skills of teachers based on evidence-based methods. The present study aimed to perform a systematic review of the professional development program for teaching teachers based on evidence-based practices for students with ASD.

Method: In this study, through systematic reviews and search for specialized keywords in Elsevier, Scopus, Google Scholar, ProQuest, Springer, and PubMed databases between 2000 and 2018, the findings and information needed to achieve the research goal was obtained. In the next step, all selected articles were reviewed by three research authors in EndNote software and duplicate articles were removed, and 217 published articles were considered base on the inclusion criteria and quality assessment using Cochrane risk of bias quality assessment. Then, based on the final qualitative evaluation, 14 articles were selected in English and reviewed in order to answer the research questions.

Results: Among studies, education in behavioral context with nine studies (45 percent), communication context with seven studies ( 35 percent), social context with three studies ( 15 percent), education context with one study ( 5 percent), and transfer and play context without study, from most to least research to allocuted themselves; also, 25 percent of the studies used in behavioral interventions and positive behavioral-supportive strategies, 15 percent of the naturalistic intervention strategies, and discrete trial training and 10 percent pivotal response training and other strategies. Conclusion: Based on the obtained results, it is suggested that professional development programs for educating teachers with students with ASD in Iran be mostly based on positive behavioral interventions and supportive strategies. As a result, educational programs should be presented in the form of individual and combined education.

* Corresponding author: Abbas Ali Taghipour Javan, Ph.D. Student of Psychology of Exceptional Children, Faculty of Psychology and Educational Sciences, University of Tehran, Iran.

E-mail: Abbas.javan.t@gmail.com

Tel: (+98) 2161111

2476-5740/ (C) 2021 The Authors. This is an open access article under the CC BY-NC-ND license

(https://creativecommons.org/licenses/by-nc-nd/4.0/). 


\section{Extended Abstract}

\section{Introduction}

Autism spectrum disorder (ASD) is a lifelong developmental condition that is characterized by specific problems in social interaction and communication, the ability to think and flexible behavior, and perception and manage sensory stimuli (1). By increasing the prevalence of ASD, the presence of students with ASD in public schools is increasing $(5,6)$. Studies have documented report adverse outcomes and lack of services for people with ASD (13). The inclusive approach, despite its many advantages, still faces many challenges, such as preparing ordinary teachers and other students. With due attention to present students with autism disorder in public schools, the professional development of teachers' education based on evidence-based practices is an essential and urgent need. Unfortunately, the evidence suggests that dominant approaches to professional development may be insufficient to develop and implement evidence-based methods for students with ASD (9). Whereas educational strategies are successful for some students with ASD; they may not be sufficient for others (24); Teachers of students with ASD should be prepared to work with these students in different efficacious ways. In general, evidencebased methods are vital for educating students with ASD; because they are an identification tool for validating teaching methods that are likely to help improve outcomes $(12,17)$. On the other hand, research shows that teachers are reluctant to use evidence-based methods in teaching autism, and evidence-based professional development models for the inclusion of students with ASD have not been widely used in schools (44). On the other hand, according to the requirements of the document of fundamental change in education in Iran to improve the job potential of teachers and the development of inclusion, as well as lack of familiarity and use of evidence-based methods by teachers and professionals despite emphasizing their effectiveness. The present study aimed to perform a systematic review of the professional development program for teaching teachers based on evidence-based practices for students with ASD.

\section{Method}

This is a systematic review with the Cochran index. Associated studies with the professional development program of teachers of people with ASD based on evidence-based methods were found and examined. The findings of the present research were based on studies conducted in the period 2000 to 2018 and included articles published in reputable journals and searches on scientific websites: Elsevier, Scopus, Google Scholar, ProQuest, Springer, PubMed. To achieve the goal of the study, findings and information were obtained. To selecting studies, all articles were extracted from the intended databases using specialized keywords by three research authors in EndNote software then we removed the recurrent articles. 217 articles were considered base on the inclusion criteria, which include 1) been published in a scientific research journal. 2) The participants in the program were teachers or those involved in the educational system (instructor, consultant). 3) At least one type of teacher training has been manipulated as an independent variable. 4) Teacher training is based on one of the evidence-based methods in autism education based on the table of Adam et al. 5) Participants have access to individuals and students with ASD and 6) The year of publication of the article is between 2000 and 2018; Selected. To evaluate the quality of articles, Cochran bias risk assessment tool based on 7 evaluation criteria (bias in random sequence, secret sequence allocation, researcher and participant blindness, evaluation of research results, presentation of incomplete results, presentation of results, and other potential sources of bias), and obtaining a minimum score of $50 \%$ of the bias risk assessment tool was used; the quality assessment was evaluated by using Cochran index bias risk measurement tool. Then, based on the inclusion criteria and final quality evaluation, 14 articles were selected in the English language and analyzed to answer the research questions. 


\section{Results}

In 13 articles that reported the number of teachers (regular teachers, special education, accompanying teachers, and educators, and staff related to autistic students), the number was 451 , and in an article, the number of teachers was unknown, and the participants were children with ASD. The participants were 280 women $(62 \%)$ and 170 men (38\%). Among the specific participants in 13 articles, 193 were general education teachers $(43 \%)$, 148 were special teachers (33\%), 62 were educators $(14 \%)$, and 49 were $(10 \%)$ without mentioning the title of the activity and only the title of staff and category. Stakeholders were involved in intervention programs. Participants ranged in age from 21 to 58 years. According to the classification report of participants in the history of attending in-service training for autism in ten articles, $61 \%$ of participants had a history of attending training courses for people with autism. Of the ten articles available on data participants' qualifications, 54\% had a master's degree, $31 \%$ had a bachelor's degree, and $15 \%$ were pursuing a university degree. All students $(\mathrm{n}=329)$ had ASD; they were categorized into three levels, in need of some supports (67\%), in need of substantial supports (20\%), and finally in need of very substantial supports (13\%). In between researches, education in behavior context with nine studies (45 percent), communication context with seven studies (35 percent), social context with three studies (15 percent), education context with one study (5 percent), and transfer and play context without the study, from most to least research to allocated themselves; also, 25 percent of the studies used in behavioral interventions and positive behavioralsupportive strategies, 15 percent of the strategies for naturalistic intervention, and discrete trial training, and ten percent pivotal response training and other strategies. In 14 studies considered, nine studies (50 percent) used individual education, six studies (33 percent) group education, and three studies (17 percent) self-education. Programs density was reported in more than 85 percent of studies, between one day to five days; and from two hours to 18 hours. In the studies reviewed, the results of most studies (11 studies) indicate the use of the coaching element as an efficacious component in the effectiveness of the professional development program, the stability of its results.

\section{Conclusion}

Evidence shows that behavioral intervention methods have the most compelling evidence for teaching education skills and reducing behavioral impairments in the classroom $(28,47)$. Therefore, according to these findings, it is considering that the professional development programs for the training of ASD students in Iran should conclude with behavioral interventions and positive behavioral support strategies; this finding is consistent with current experiences in professional development programs (25). Evidence indicates that the coaching element has improved teachers' use of evidencebased methods in educating students with ASD; also, training that includes coaching or action feedback increases teachers' level of commitment and adaptation to evidence-based procedures (45). Based on the findings, it is noticeable that coaching in professional development programs is necessary and urgent for the continued use of evidence-based methods, maintaining the quality of training and fidelity to methods taught over a long period. In general, the results show that despite the great work that has been done in the field of professional development of teachers and students with ASD, the structure of professional development programs based on needs and facilities is adaptive and given that teaching academic skills and reducing behavioral impairments in the classroom are among the priorities of teachers in educating students with autism. In the present study, the lack of review of the taught content, cultural issues, and how to follow the presented programs, including the limitations of the study and the lack of access to some articles were methodological limitations in this systematic review. 


\section{Quarterly Journal of Child Mental Health}

Vol. 8, No. 1, Spring 2021

\section{Ethical Considerations}

Compliance with ethical guidelines: This article is extracted from the Ph.D. dissertation of the senior author, which was approved in which was approved in the field of Psychology of Exceptional Children at Tehran of University, with the number 354653 and successfully defended on 01 OCT 2019.

Funding: This study was conducted without the financial support of any public or private institution or organization.
Authors' contribution: This article is extracted from the Ph.D. dissertation of the corresponding author. First author is the supervisor and the third and the fourth ones are the advisors. Conflict of interest: No conflict of interest was declared by scholars.

Acknowledgments: We would like to thank all those who contributed to the collection of research data. 


\title{
برنامه توسعه حرفهاى آموزش معلمان بر اساس تمرينات مبتنى بر شواهد براى دانش آموزان با اختلال طيف اوتيسم: مطالعه مرورى نظامند
}

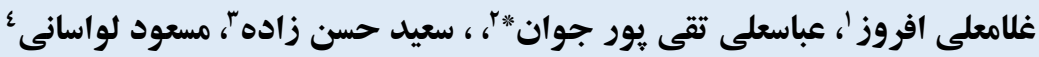

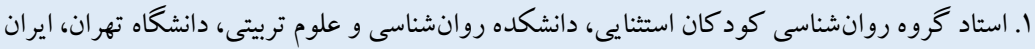

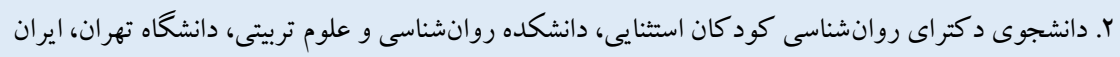

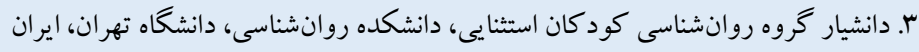

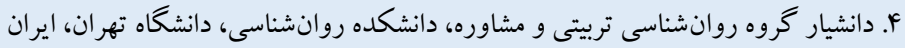

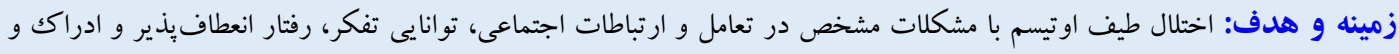

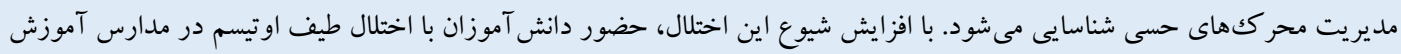

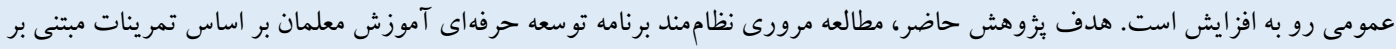
شواهد براى دانش آموزان با اختلال طيف اوتيسم است.

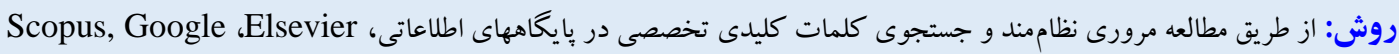
مشخصات مقاله بubMed، Springer ،ProQuest ، Scholar

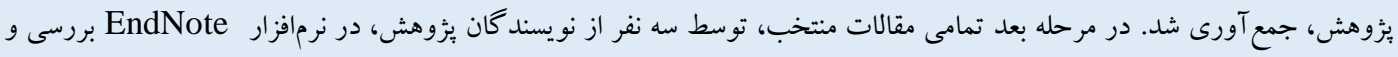

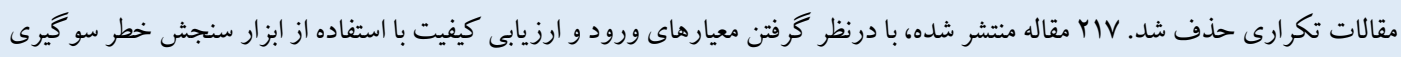

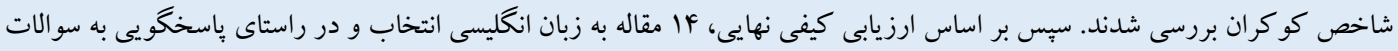

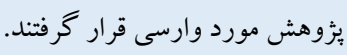

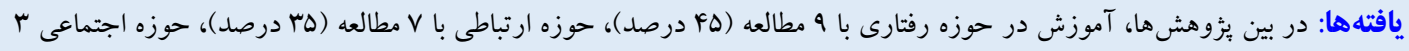

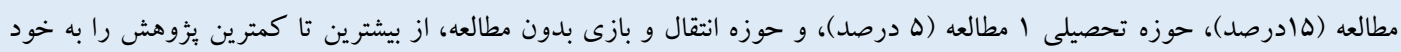

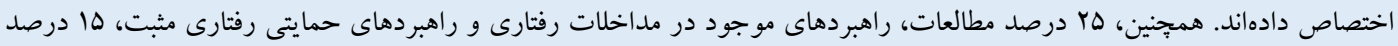

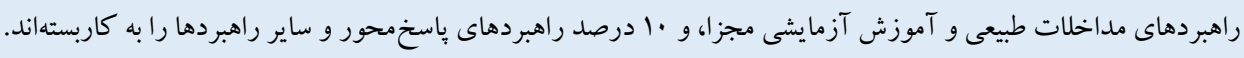

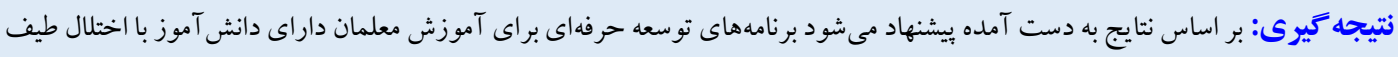


ويزه افزايش دهد ( ·Y). متأسفانه شواهد نشان مىدهد كه روى آوردهاى

مقدمه غالب براى توسـعه حرفهاى ممكن اسـت براى ايجاد و اجر ايى روشهاى

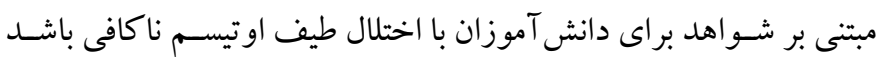

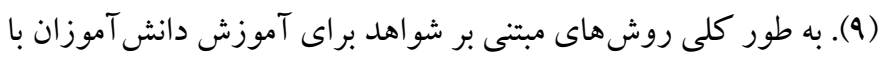

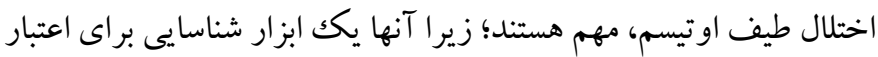

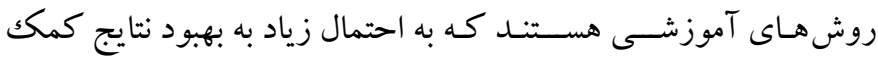

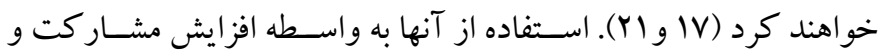

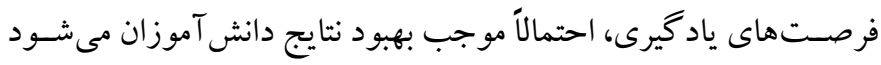

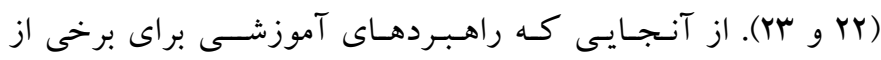

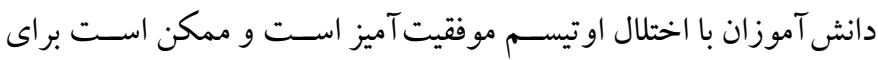

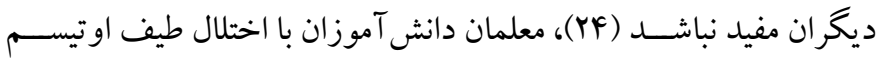
مىبايسـت با شـيوههاى مختلف مؤثر براى كار با اين دانش آموزان آماده

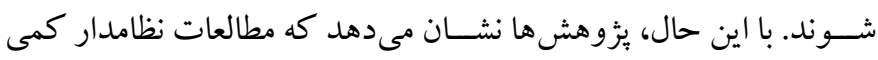
براى اطمينان از حصسول نتايج شيوههاى مؤثر وجود دارد (Yه). إب شيوه

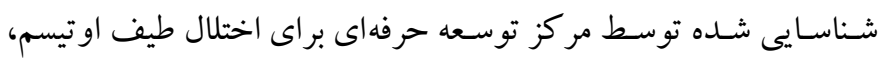

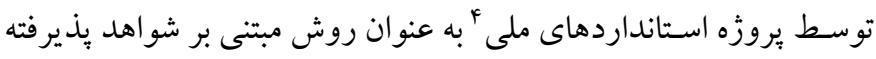

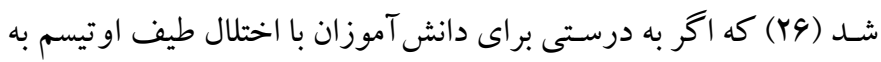

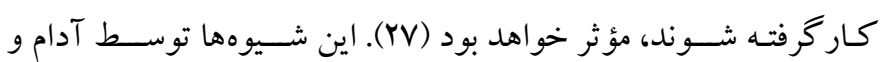

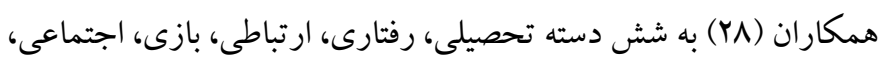

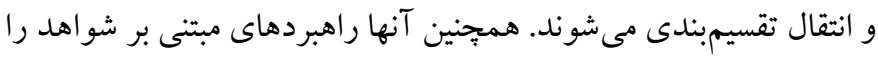

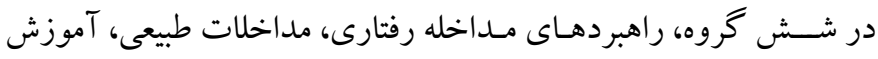

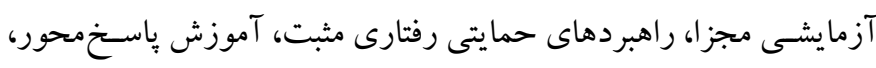

$$
\text { و ساير راهبردها دستهبندى كردند. }
$$

درحالى كه برنامههاى توسـعه حرفهاى براى معلمان داراى دانش آموز

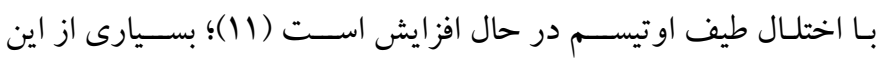

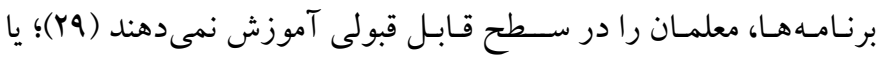

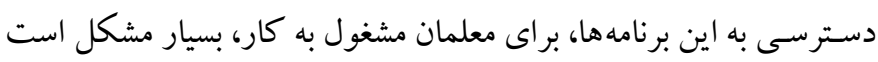

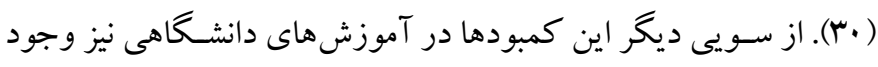

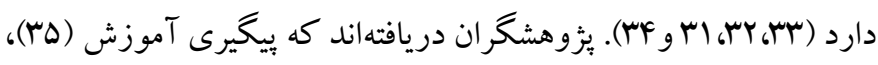

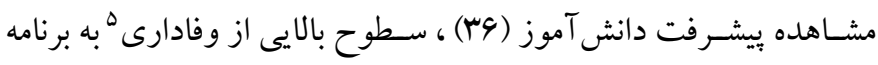


() با توجه به طبقهبندى آدام و همكاران (YN)، برنامهاى توسعه حرفهاى

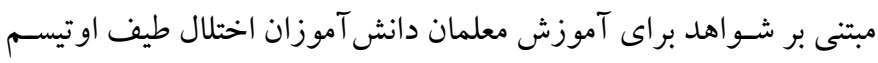

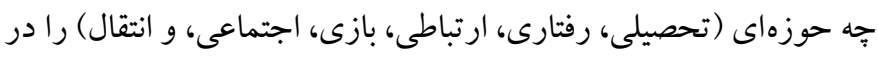
برمى گيرد؟ (r) ابعاد آموزش معلمان (خودآموزشى، آموزش فردى، آموزش گروهى) در برنامه توسعه حرفهاى اختلال طيف اوتيسم كداماند؟

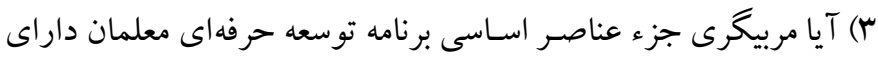

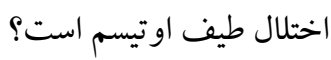

روش

يُزوهش حاضـر از نوع مطالعه مرورى نظاممند' بود كه از طريق شـاخص

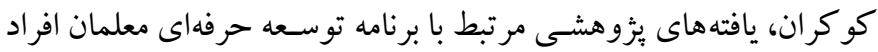

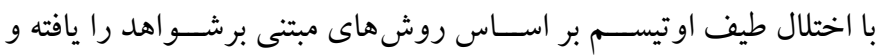
بررسى كرد. يافتهاى اين جسـتجو و بررسى بر اسـاس مطالعات انجام

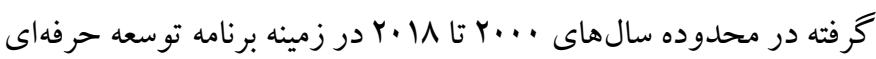

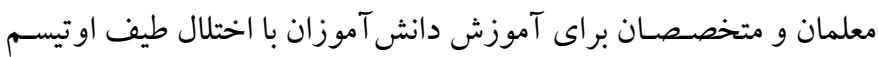
بر اسـاس روش هاى مبتنى بر شـواهد انجام شـدهه و شـامل مقالات جاب

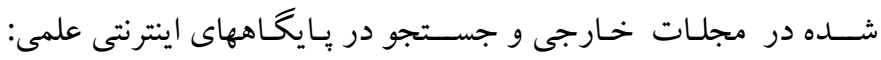

و SPringer ،ProQuest ،Google Scholar ،Scopus، Elsevier professional بـا جسـتجوى كلمـات يـا عبـارات كوتـاه PubMed in-service teaching for teacher steaching teacher ،development ،coaching for autism training educator or teacher or staff training teacher for, cevidence based training for autism student with ASD in public schiil

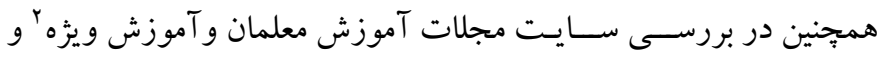

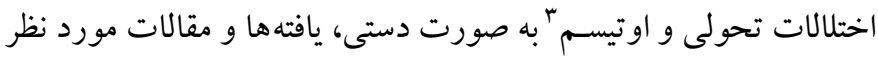
در راسـتـاى ســوالات يُزوهش مورد واكاوى قرار گرفت. در ابتدا تمام

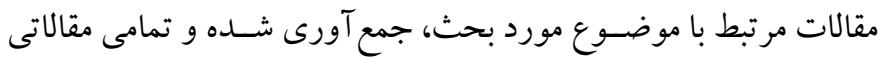
كه مرتبط با برنامه توسعه حرفهاى براى اوتيسم، آموزش معلمان اوتيسم،

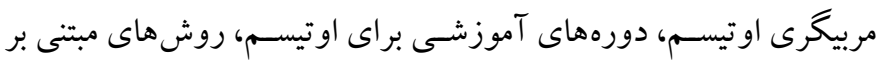

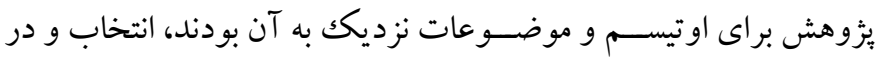

3. Journal of Autism and Developmental Disorders r. ) و متناسـبـسـازى و تغيير هسـته يا اجزاى برنامه توسـط معلمان (YV)

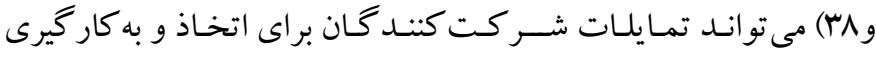
شـيوههاى جديد و اثربخشى برنامه توسـعه حرفهاى معلمان براى آموزش دانش آموزان با اختلال طيف اوتيســم را بالا بيرد. از آنجايى كه يزوهش ها نشـان مى دهد معلمان به اسـتفاده از روش هاى مبتنى بر شواهد در آموزش

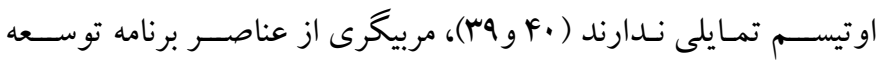
حرفهاى اسـت كه مى تواند اسـتفاده از شـيوههاى مختلف اقدامات مبتنى برشـو اهد را بهبود ببخشد (FI). مربيكرى مى تو اند شامل طيف مختلفى از تمرينات ويزٔه شـود (Fr)؛ اما به طور معمول شـامل بازخورد كاركردى و خودبازخوردى است (FT). جامعه يثزوهشى تلاش كرده است تا با استفاده از اسـتانداردهاى دقيق براى انتخاب و انتشـار راهبردهايى كه در مطالعات تجديد نظر شده، ظاهر مىشوند، بر روى روش هاى مبتنى بر شواهد براى

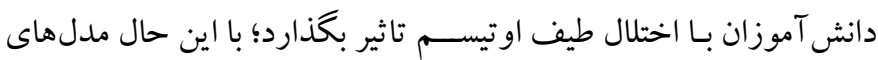
توسعه حرفهاى مبتنى بر شـو اهد به طور گسترده در مدارس استفاده نشده

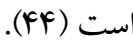

با توجه به الزامات سـند تحول بنيادين آموزش و يرورش در راسـتاى بهبود توان شـغلى معلمان و توسعه فراگيرسـازى، همجنين كمبود منابع و بيشـينه يُزوهشـى مربوط به توسـعه حرفهاى معلمان در مدارس آموزش عمومى براى يـذيرش و آموزش دانش آموزان با اختلال طيف اوتيســـم و عدم آشــنايى و به كار گيرى روش هاى مبتنى بر شـو اهد توســ معلمان و متخصسصـان با وجود تأكيد بر اثربخشسى آنها، ضـرورت انجام يثزوهش حاضـر در ايران دوجّندان مى شـود. يافته هاى يُزوهش حاضـر مى تو اند در تدوين برنامههاى توسـعه حرفهاى به منظور آموزش معلمان دانش آموزان با اختلال طيف او تيسم مورد تو جه قرار گيرد. اين مطالعه در راستاى ياسخ بـه خلـاء مو جود در حوزه برنـامـه توســعه حرفهاى معلمان براى آموزش دانش آموزان با اختلال طيف اوتيسـم بر اساس روش هاى مبتنى بر شواهد، تلاش كرده است، ييشينه يُزوهشى برنامه هاى توسعه حرفهاى معلمان مبتنى بر روش هاى شـواهدمحور در خارج از ايران را مورد بررسسى قرار دهد تا تـا

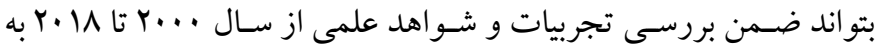
سوالات زير ياسخ دهد.

1. Systematic review

2. Journal Teacher Education and Special Education 
يُروهش، در نرمافزار EndNote بررسـى و موارد تكرارى حذف شـــــ.

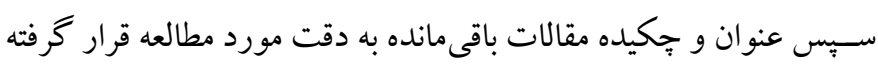

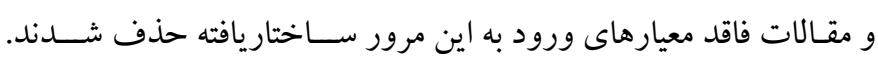

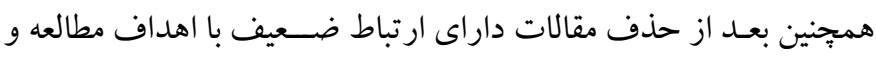

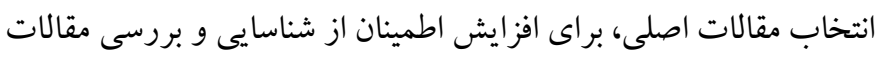

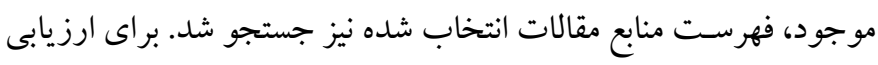

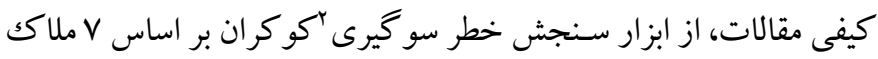

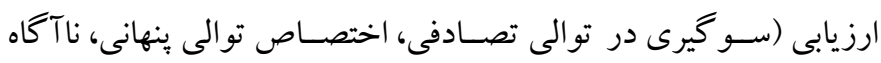

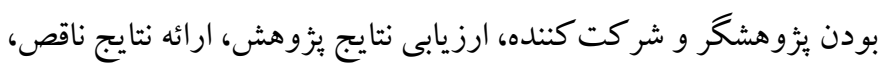

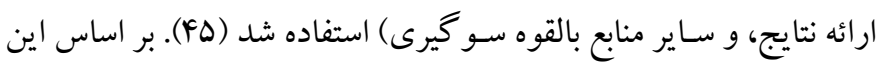

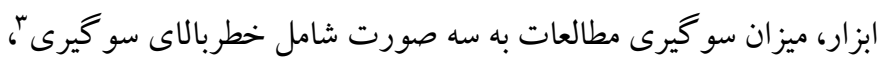

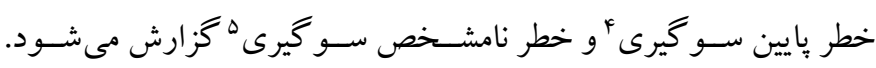

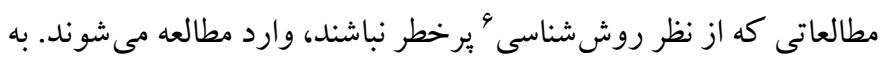

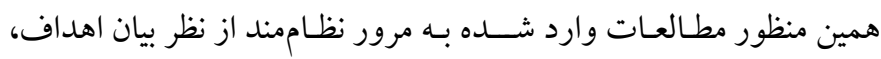
زمان انجام مطالعه، توصيف انتخاب شر كت كنند گان و حجم نمونه، ابزار

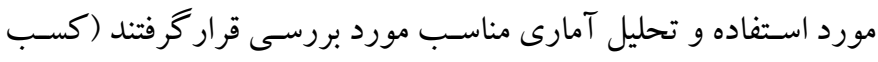

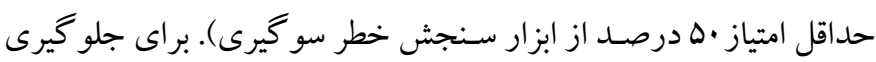

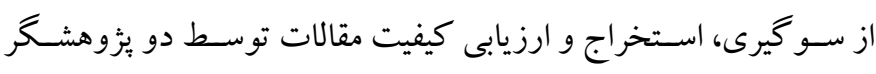

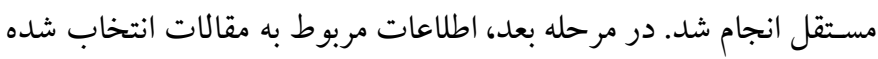

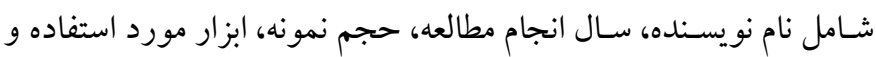
متغير ارزشيابى شده با هدف مطالعه حاضر در جدول ا ثبت شد.
فهرسـت اوليه مقالات قرار داده شدهاند. سبس بر اساس معيارهاى ورودى

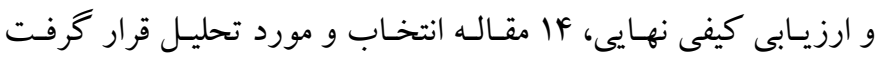

\section{الف) معيار انتخاب مقالات}

معيارهاى ورود به مطالعه شـامل مقالات موجود در ارتبات معال بات با برنامه توسعه

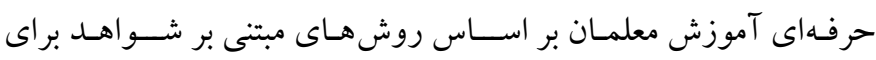

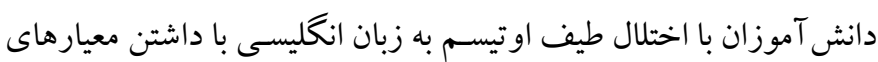

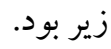
الف) در يكك مجله علمى برُوهشى جابٍ شده باشد، ب) شر كت كند گَان در برنامه به عنوان معلم يا دسـتاندر كار سـيستم آموزشى (مربى، مشاور)

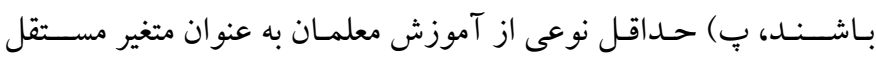

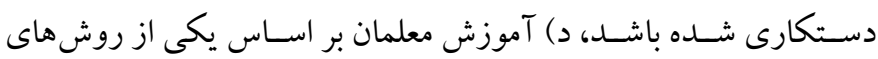
مبتنى برشـواهد در آموزش اوتيسـم بر اساس جدول آدام، بيد، هال و هام

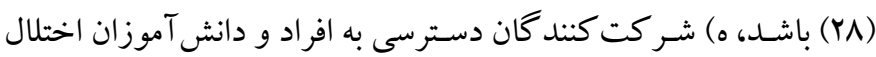

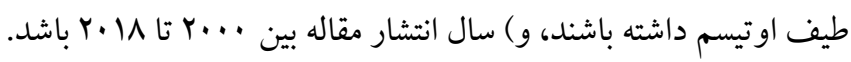

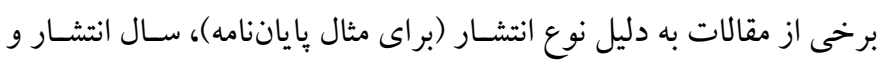

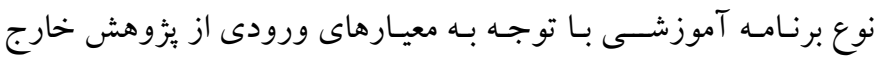
شدهاند.

\section{ب) ارزيابى كيفيت مقالات} بر ايى انتخاب مطالعات، تمامى مقالات بعد از استخر اج از بايكاهـهاى مورد نظر با استفاده از كليدوازههاى تخصصىى، توسط سه نفر از نويسند كان
4. Low risk of bias

5. Unclear of bias

6. Metodology
1. Inclusion criteria

2. Risk of bias

3. High risk of bias 


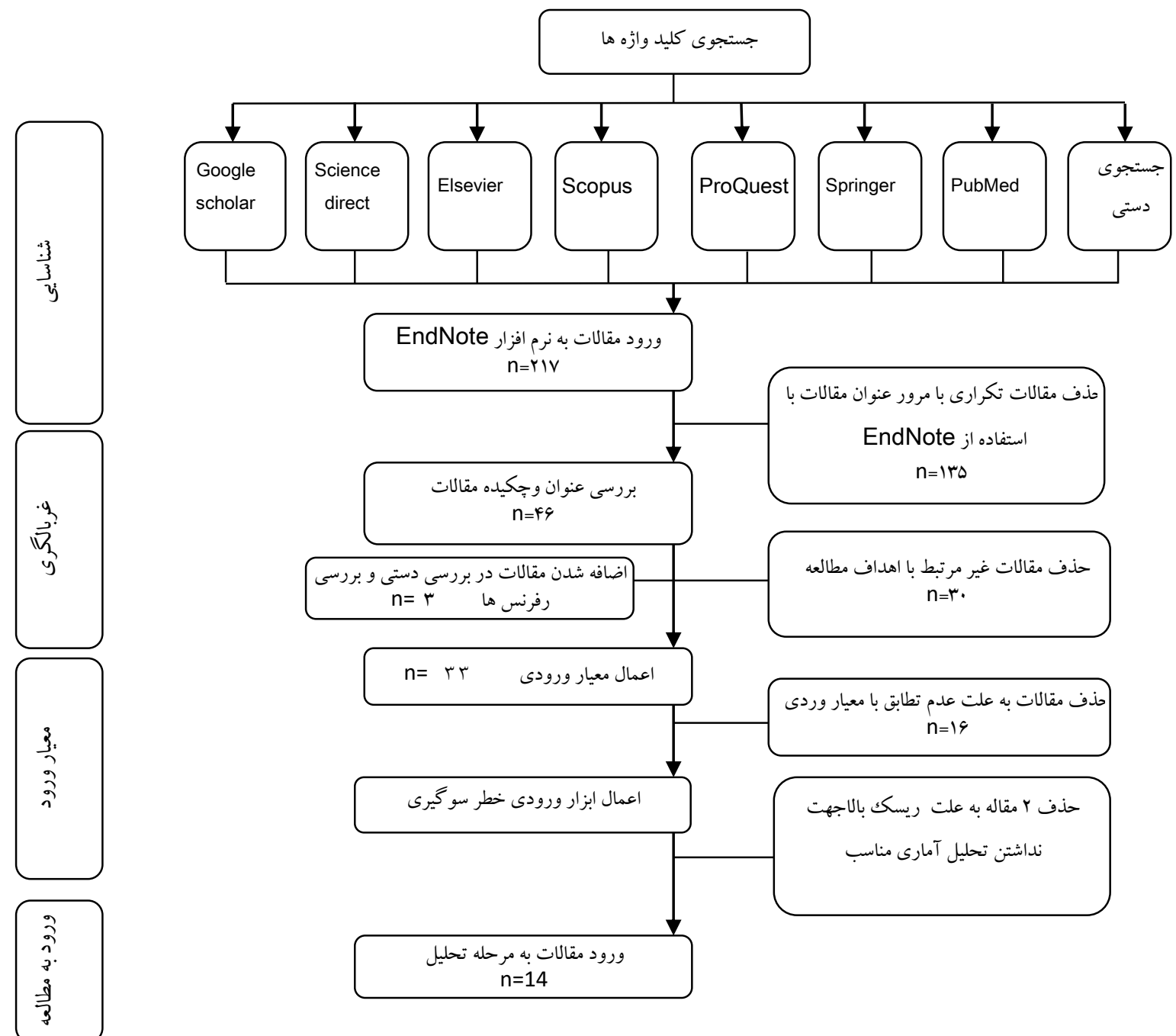

شكل ا: روند ورود مطالعات به يروزه

فعاليت و صرفاً با عنوان كار كنان و دستاندر كاران، در برنامه هاى مداخله يافتهها

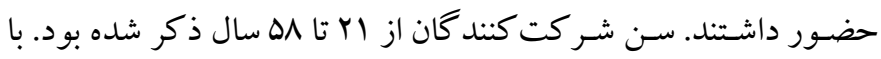

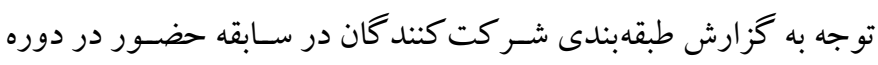

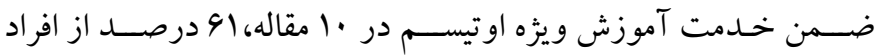
شـر كت كننده سـابقه حضـور در دورههاى آموزشسى ويزه افراد با اختلال

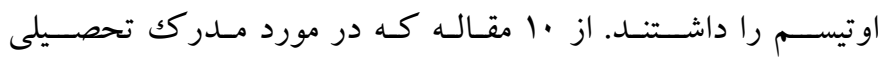

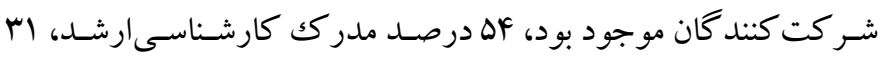

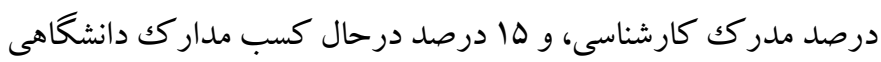

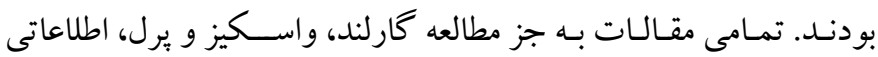
درباره دانش آموزان كه در مداخلات حضسور داشتند يا معلمان آنها، ارائه

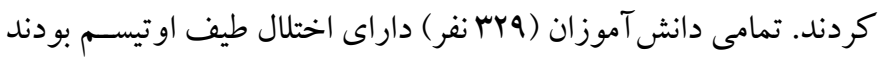

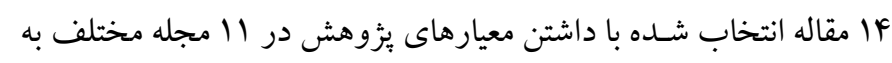
جاب رسيده بود كه مجله آموزش معلم و آموزش ويزهه با م مقاله بيشترين مقاله را داشـت. در با مقالهاى كه تعداد معلمان (معلمان عادى، آموزش ويزه، معلمان همر اه و مربيان و كار كنان مرتبط با دانش آموزان اوتيسـم) را دان

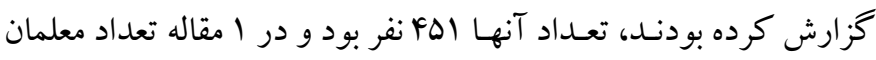

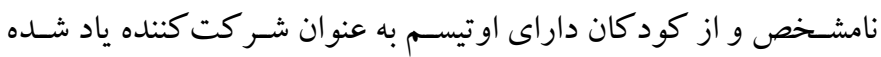

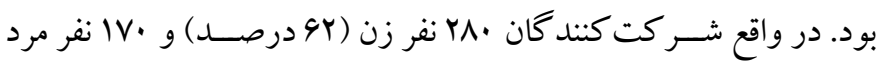

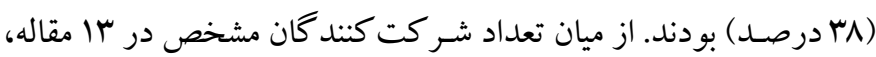

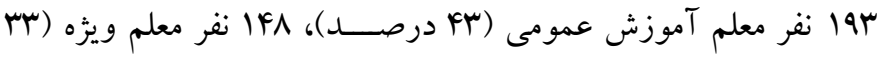

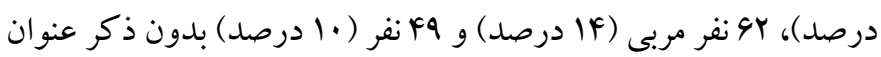


مطالعه از F تا مل سال گز ارش شده بود. اطلاعات كلى مقالات در جدول ارائه شده است.
و در سـه سـطح، نياز به نظارت و حمايت (9V درصـد)، نياز به نظارت و

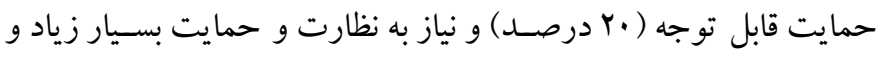

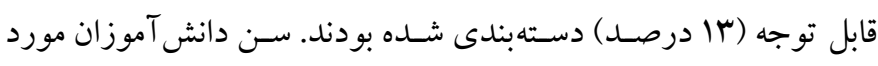

جدول ا: مقالات بركزيده شده با توجه به معيارهاى ورود به يذيرش

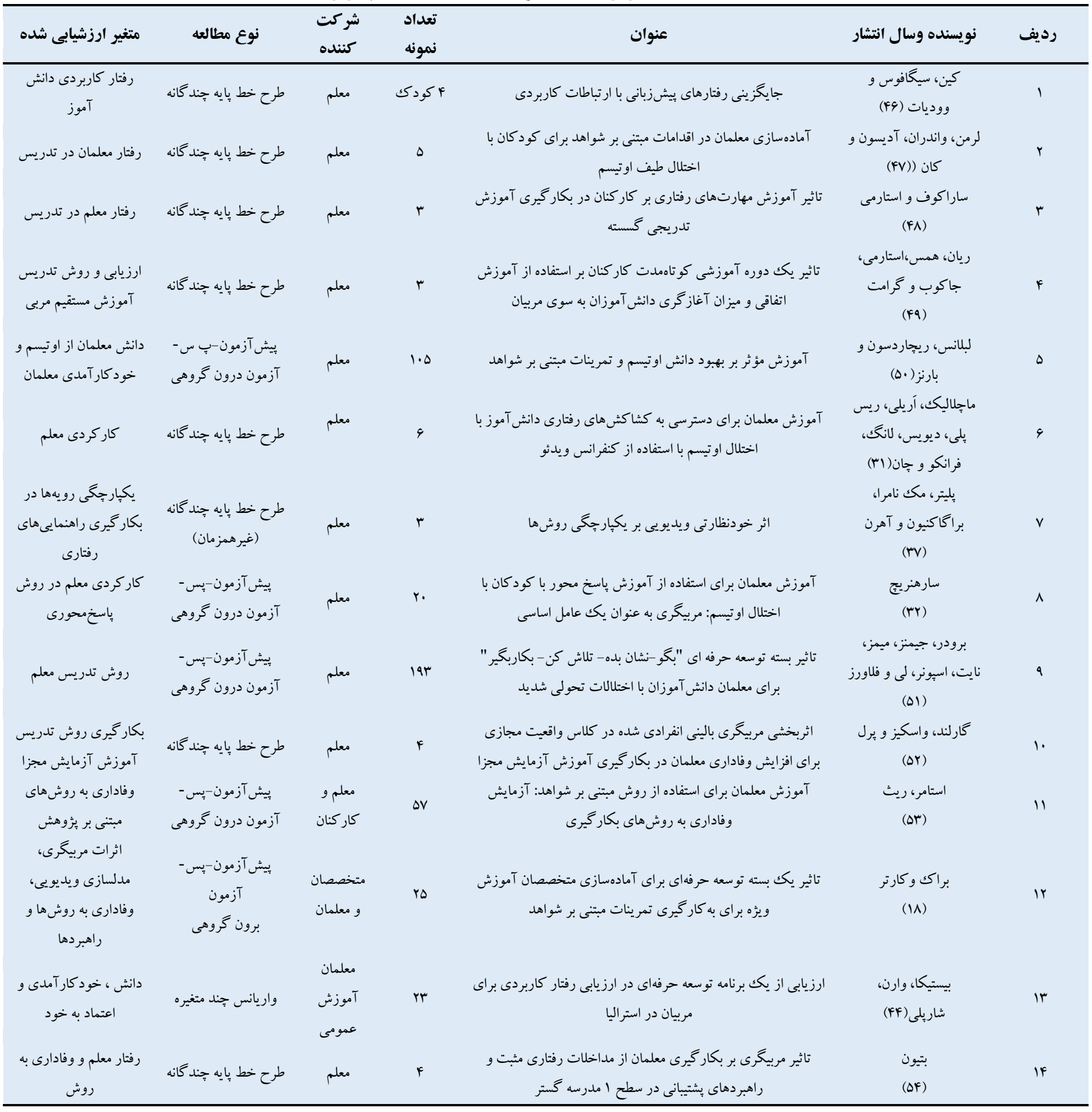


جدول r: راهبردها، ابعاد و حوزه آموزش مقالات مورد بررسى

\begin{tabular}{|c|c|c|c|c|c|}
\hline مربيكرى & حوزه آموزش & ابعاد آموزش & راهبرد مبتنى بر بزوهش & نويسنده وسال انتشار & رديف \\
\hline دارد & ارتباطى - اجتماعى & فردى & مداخلات طبيعت گر ايانه & كين، سيكافوس و ووديات (r...1) & 1 \\
\hline دارد & 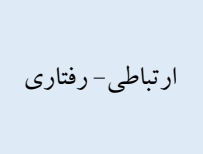 & 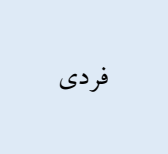 & مداخلات طبيعت كرايانه & 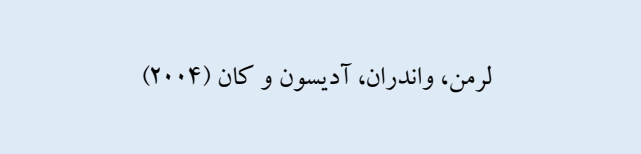 & r \\
\hline 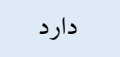 & رفتارى- ارتباطى & فردى & آموزش آزمايشى مجزا & ساراكوف و استارمى (FF) & $r$ \\
\hline ن ارد & 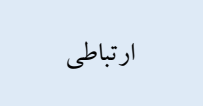 & خودآموزشى & مداخلات طبيعت كر ايانه & 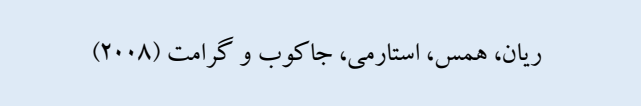 & $r$ \\
\hline ن ارد & رفتارى & 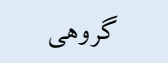 & راهبرد مداخلات رفتارى & كبلانس، ريجاردسون و بارنز (ج. . . ) & $\Delta$ \\
\hline 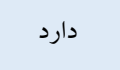 & 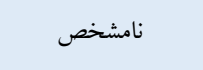 & 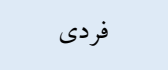 & راهبردهاى حمايتى رفتارى مثبت & 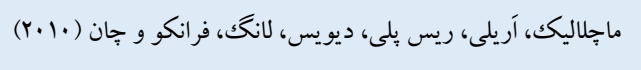 & 4 \\
\hline ن ارد & ن امشخص & خودآموزشى & راهبردهاى حمايتى رفتارى مثبت & 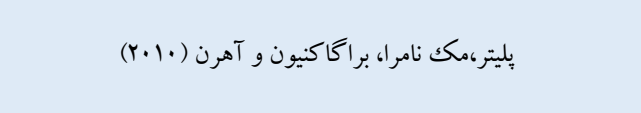 & $v$ \\
\hline دارد & تحصيلى-رفتارى & فردى، خروهمى & تمرينات باسخ محورى & 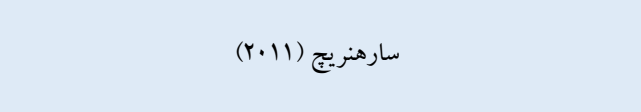 & $\wedge$ \\
\hline دارد & 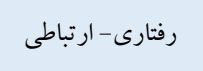 & 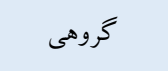 & ساير راهبردها & برودر، جيمتز، ميمز، نايت، اسيونر، لى و فلاورز (r (r) & 9 \\
\hline دارد & ار تباطى-رفتارى & 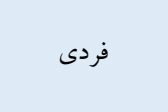 & راهموز آزماخلات رفتارى مجزا & 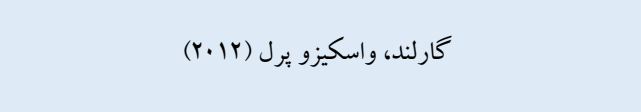 & 1. \\
\hline دارد & رفتارى & 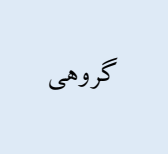 & 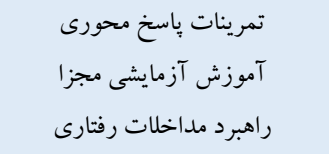 & استامر، ريث (F) (Y) & 11 \\
\hline دارد & رفتارى - اجتماعى & 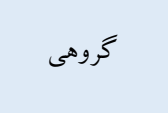 & 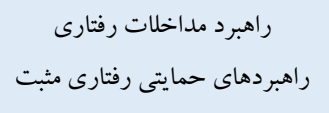 & 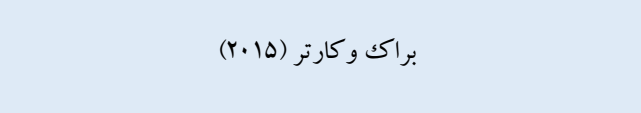 & ir \\
\hline 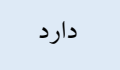 & ارتباطى- اجتماعى & 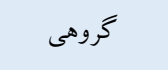 & راهبردهاى حمايتى رفتارى مثبت & 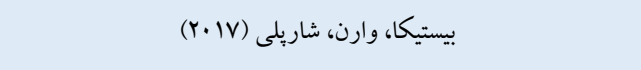 & ir \\
\hline 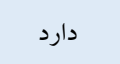 & رفتارى & فردى & راهبردهاى حمايتى رفتارى مثبت & بتيون (Y) (Y) & if \\
\hline
\end{tabular}

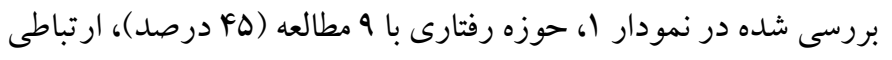

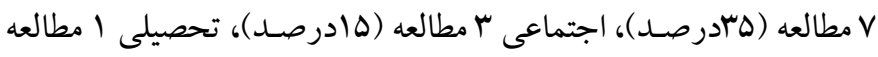

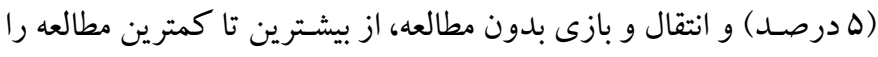

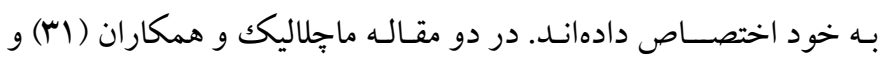

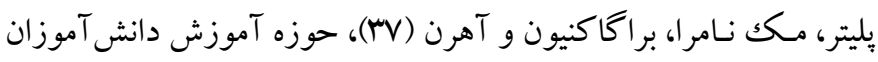
مورد مطالعه نامشخص بود.
ســوال ا: بـا توجه به طبقلهبندى آدام و همكاران (TA) برنامههاى

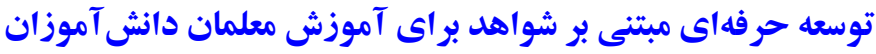

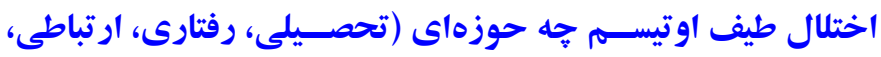

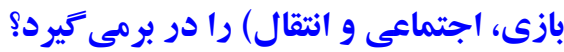

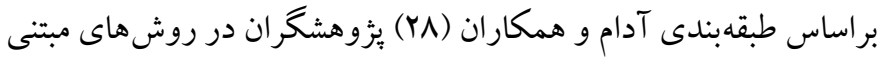

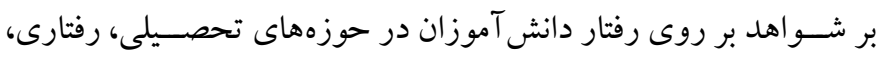
ارتباط، اجتماعى، بازى و انتقال به صـورت كلى كار كردهاند. در مقالات 


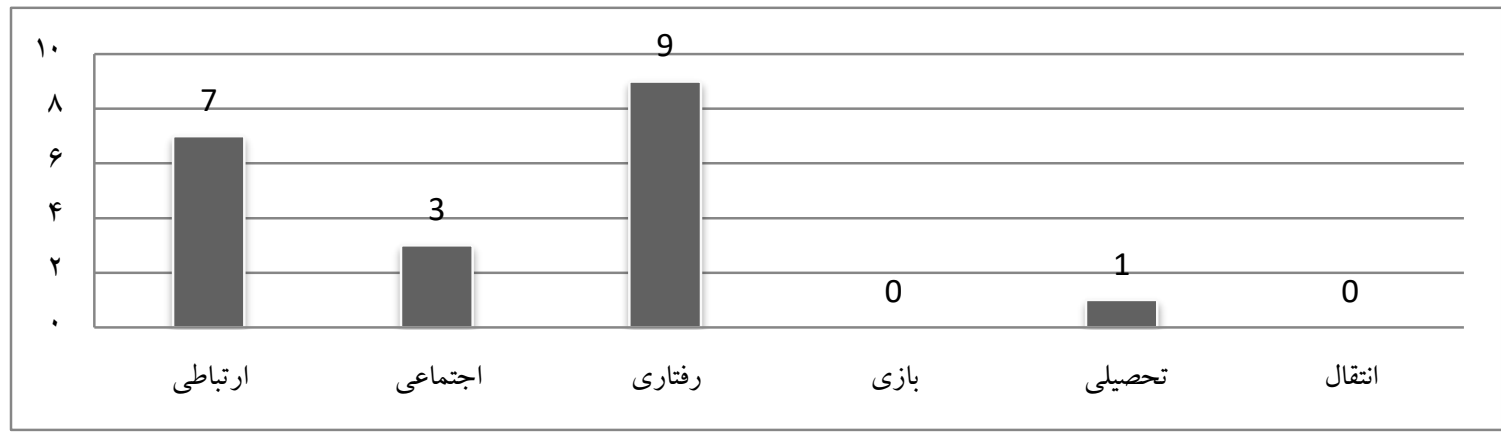

نمودار ا: حوزه آموزش برنامه توسعه حرفهاى در مقالات بررسى شده

راهبردهاى به كار گرفته شـده هسـتند؛ و راهبردهاى باسـخمحور و سـاير

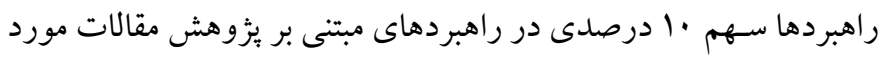
بررسى دارند.
همان طور كه در نمودار Y مشـاهده مى شـود، راهبردهاى زيرمجموعه

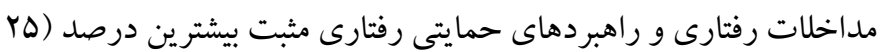

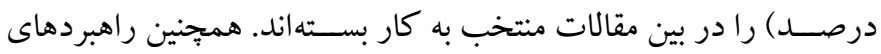

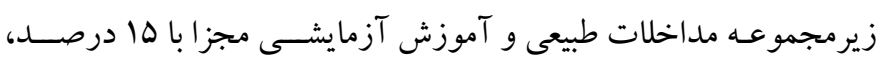

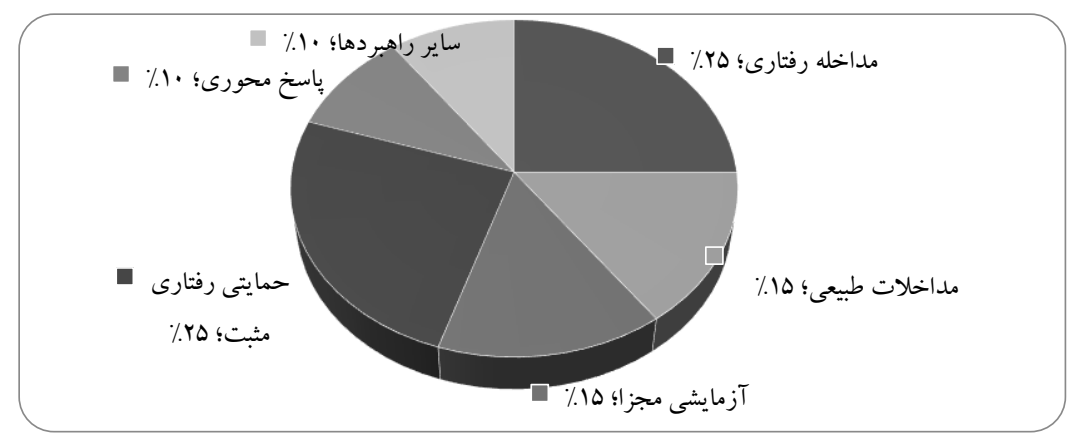

نمودار rا: راهبردهاى مبتنى بر ئوهش در مقالات بررسى شده

آموزش گُروهى - كه شــامل آموزش بيش از يـك نفر در يكك زمان و معمولاً به صورت سخنرانى، بحث و فعاليت گروهى است. نمودار ب نشان مىدهد در f(ا مطالعه بررسى شده، 9 مطالعه آموزش فردى ( •ه درصد)،

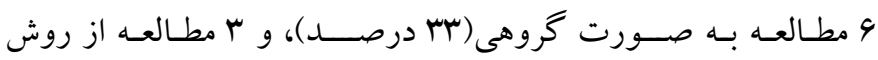
خودآموزشى (V)

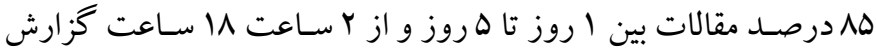
شده بود.
ســوال ז: ابعـاد آموزش معلمان (خودآموزشــى، آموزش فردى،

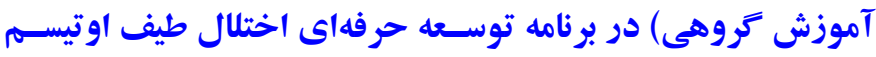

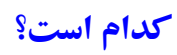

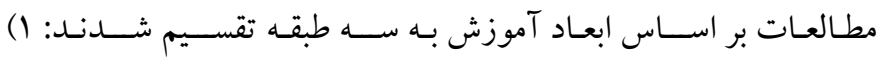

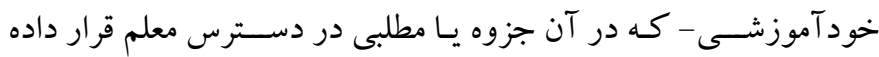
مىشـود و به صسورت خودمديريتى معلم آن را مطالعه و بررسى مى كند؛

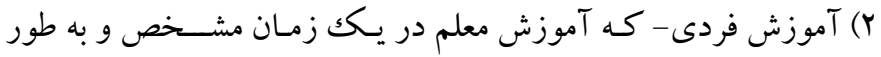

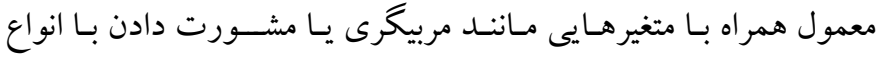

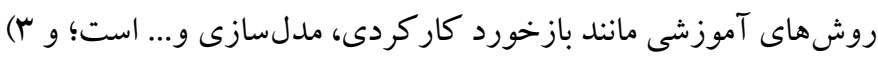




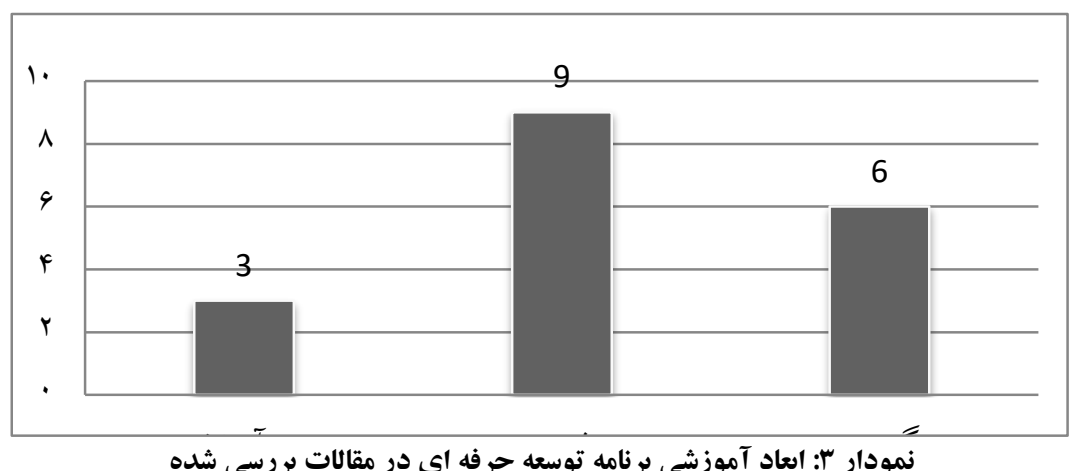

نمودار "ّ: ابعاد آموزشى برنامه توسعه حرفه اى در مقالات بررسى شده

به صـورت مربيخرى داشـتند و ب مطالعه (الب درصـد) در مداخله خود از عنصر مربيخرى استفاده نكرده بودند.
سـوال ": آيا مربيعرى جز عناصـر اســــى برنامه توسـعه حرفهاى

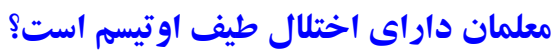

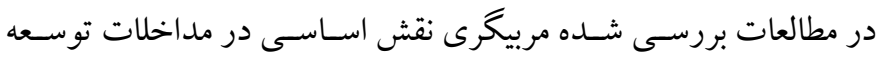

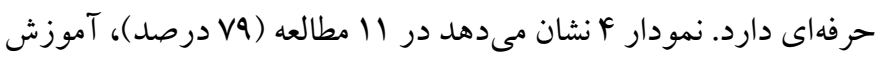

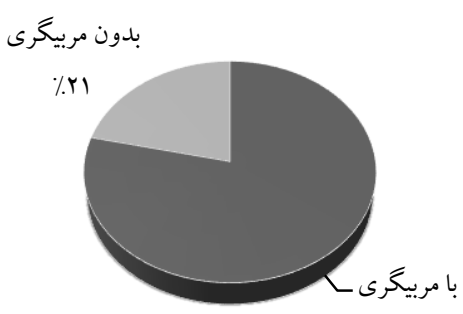

$\%$. 9

نمودار ع: وضعيت مربى كرى در مقالات بررسى شده

ديخر معلمـان در هنخـام آموزش افراد مبتلـا بـهـ اين اختلـال به آسـانى از روشهاى مبتنى بر شواهد استفاده نمى كنند (qه و • F). مو انع احتمالى اين

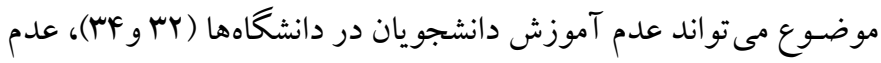

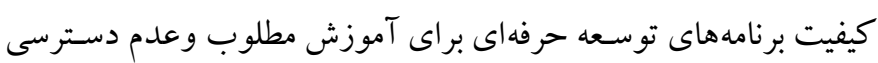

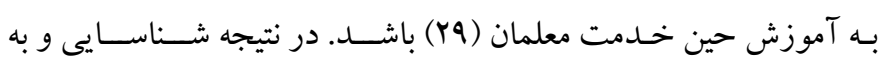

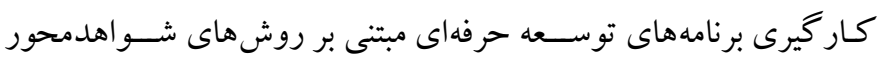

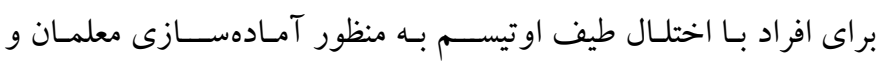

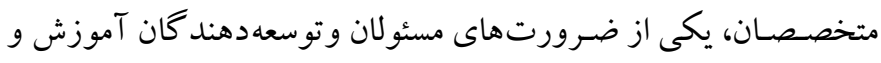

نتايج بررسى نشان داد غالب يزوهشها، راهبردهاى موجود در حوزه

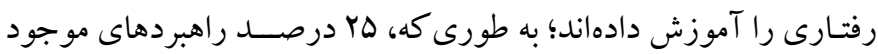
در مداخلات رفتارى و راهبردهاى حمايتى رفتارى مثبت را به كاربستهاند.

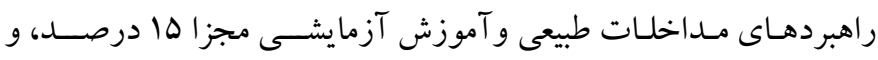

\section{بحث و نتيجه كيرى}

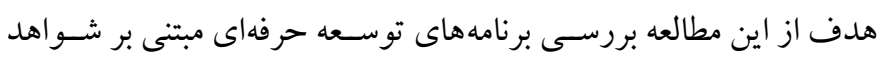

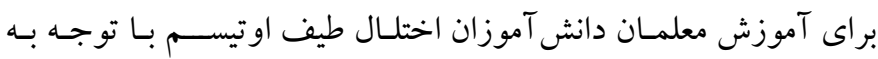

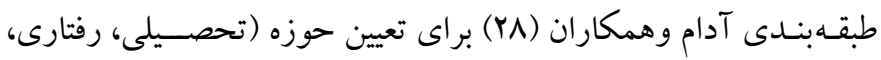

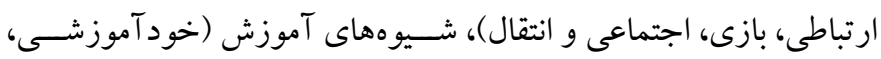

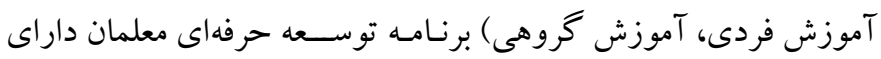

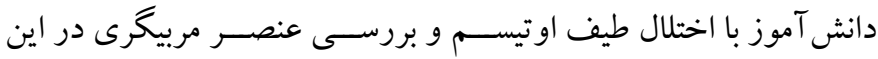

$$
\text { برنامه ها بود. }
$$

بهترين راه فراهم كردن زمينه هاى آموزشسى مؤثر در راسـتاى تحول

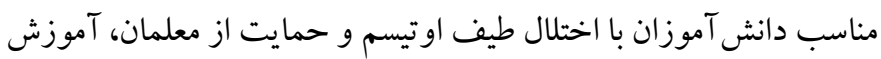
راهبردهاى مبتنى بر شواهد است (IV) با با اين وجود، از يكك سو در مورد آموزش معلمان و متخصــصــان حرفهاى كه در مدارس ابتدايى عمومى مدي

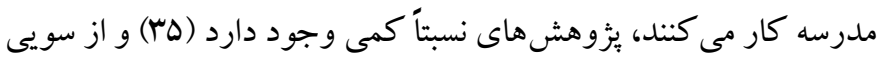


اسـتفاده كردهاند. بيشـتر مطالعات از آموزش فردى در تر كيبى با سـاير

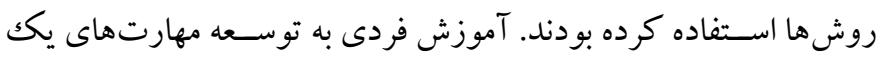

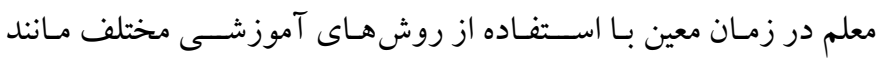

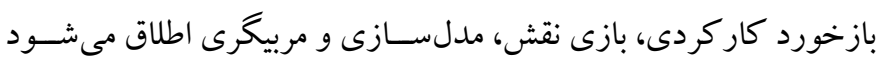

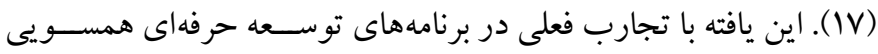

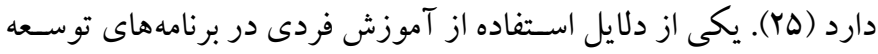
حرفهاى، ايجاد فرصـت هاى يادگيرى فعال اسـت كه باعث افزايش تعامل

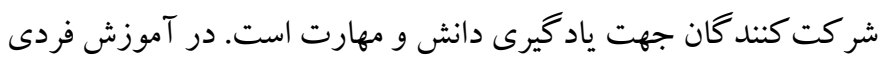

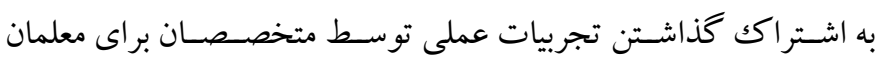

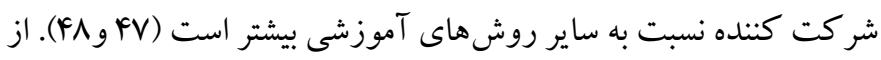
سويى تعداد كم كود كان با اختلال طيف اوتيسم كه در مدارس آموزش

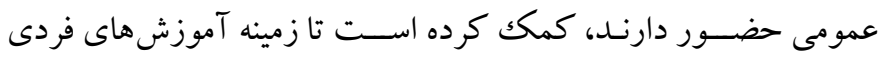

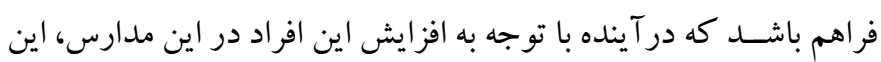

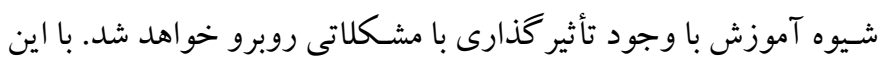

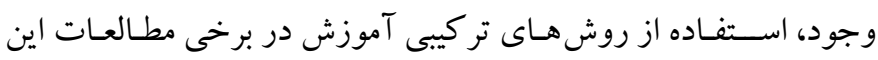

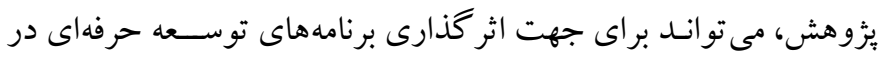
آينده مورد توجه قرار گيرد.

همانطور كه مطالعات بررسى شده نشان مى دهد مربيخرى از عناصر مرد

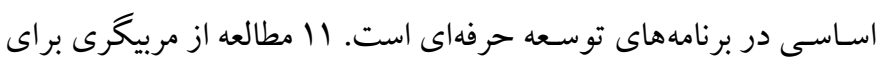

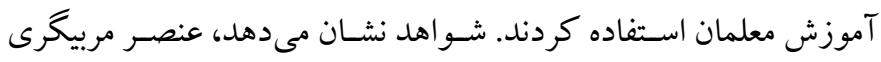

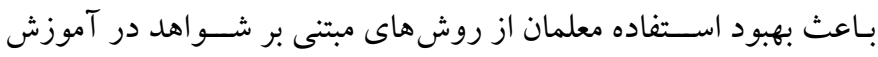

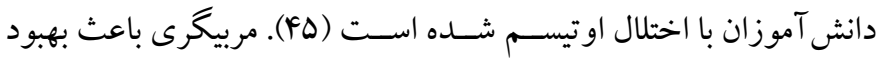
شــر ايط اســفاده از تمر ينات هدف و افزايش مشـــار كت دانش آموزان

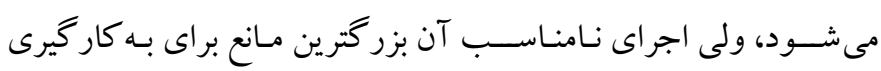

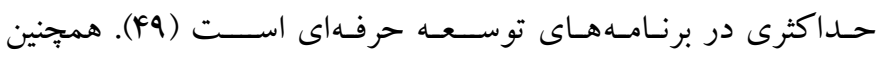

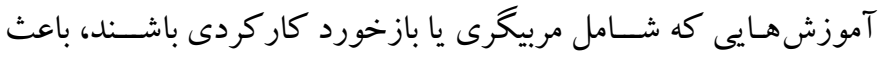

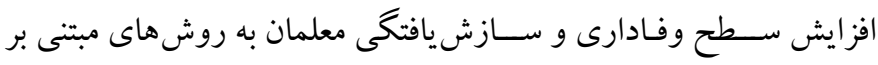

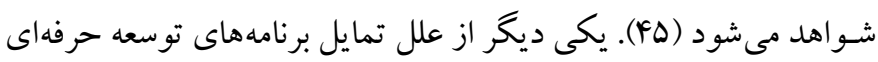

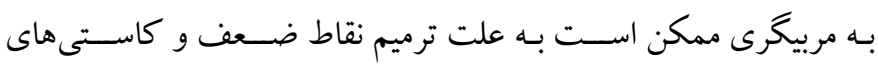

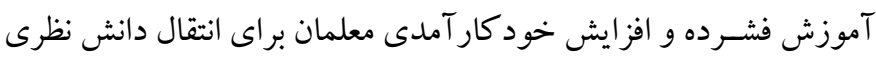

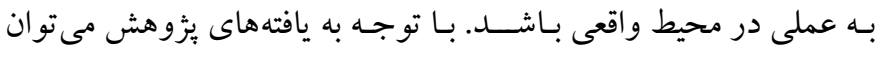

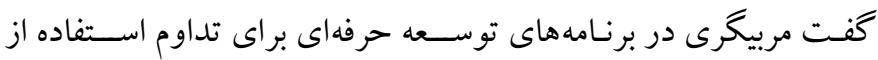

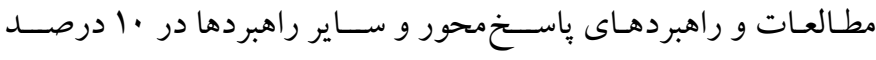
مطالعات نقش داشـتند. در تبيين اين يافته مىتوان كفت كه دانش آموزان

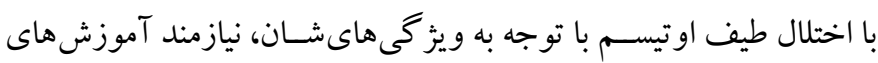

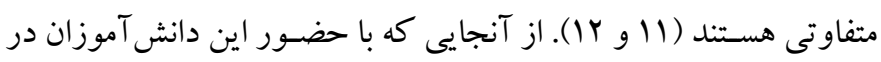

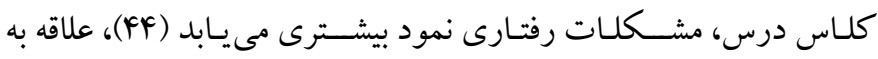

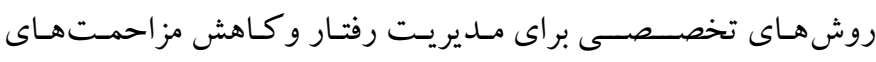

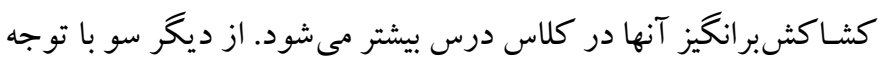

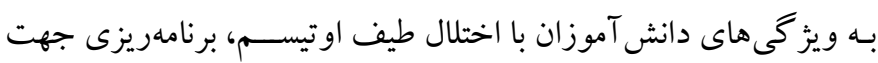

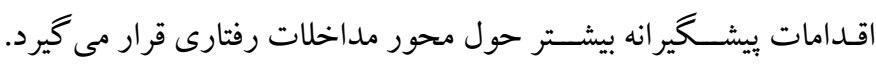
شـو اهد نشـان مى دهد روش هاى مداخله رفتارى مستدل ترين شواهد براى

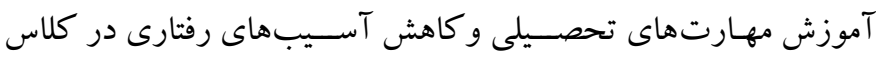

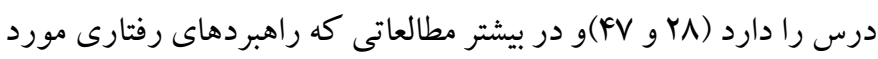

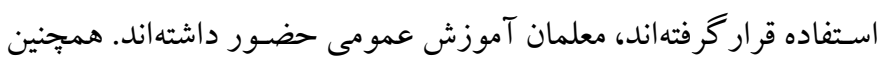

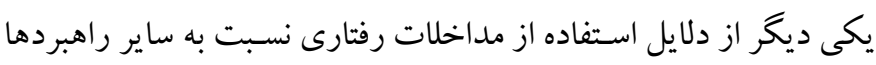

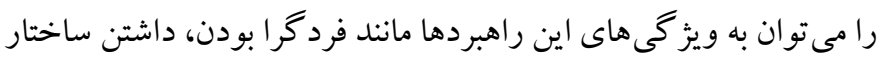

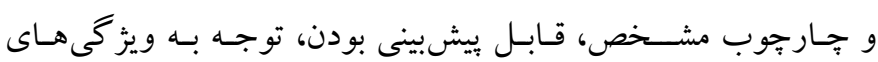

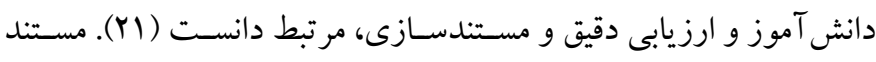

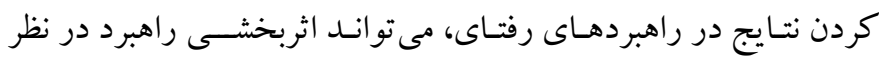

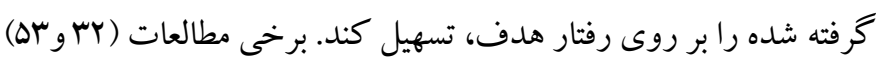

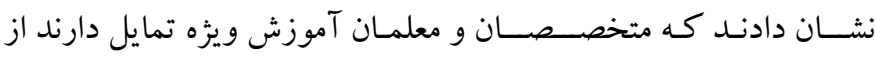
روش هاى تخصـصى تر مانند راهبردهاى باسـخمحور اسـتفاده كنند. در

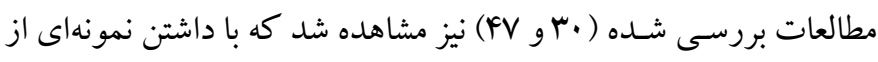

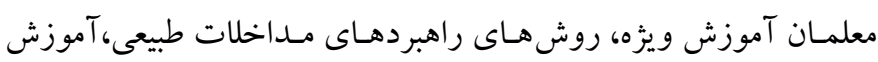

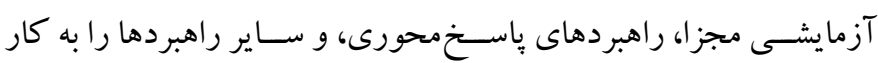

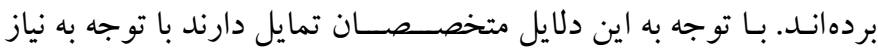

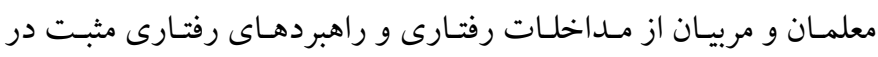
برنامهاى توسعه حرفهاى استفاده كنند.

تمرينات در سه بعد آموزش فردى، آموزش گروهى و خود آموزشى

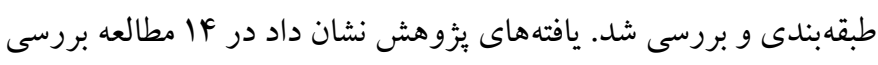

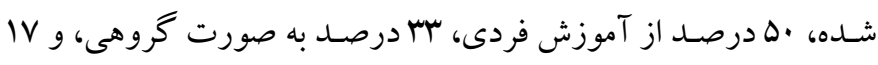

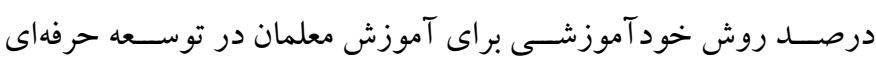


خـانواده در آموزش معلمـان، زمـان ارائهه آموزش (ضــمن خدمت/حين

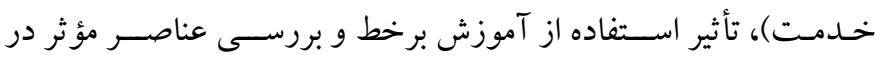

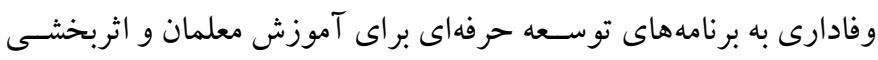

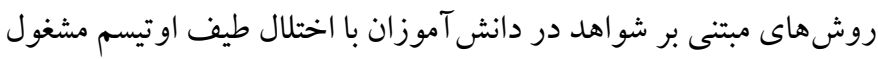

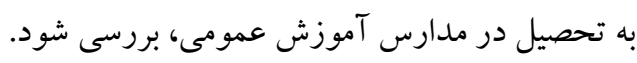

ملاحظات اخلاقى ييروى از اصول اخلاق يزوهش: اين مقاله بركرفته از رساله دوره دكتراى تخصصى

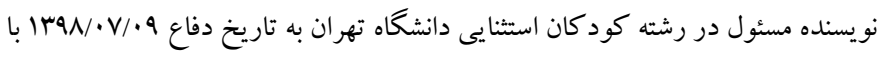

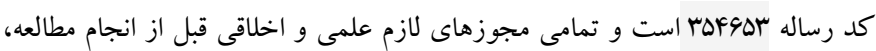

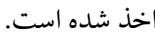

حامى مالى: اين مطالعه بدون حمايت مالى هيج مؤسسه و سازمان دولتى يا خصوصى انجام شده است. نقش هر يكك از نويسندكان: نويسنده مسئول به عنوان نويسنده اصلى اين مقاله و

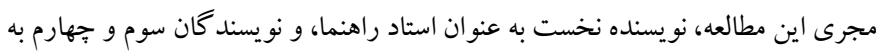
عنوان استادان مشاور در اين مطالعه نقش داشتهاند.

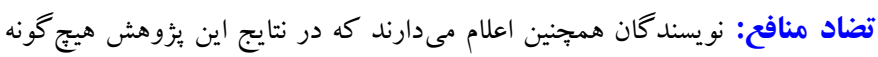
تضاد منافعى وجود ندارد. تشكر و قدردانى: بدين وسيله از تمامى افرادى كه در جمع آورى دادههاى بيزوهش يارى رساندند، تشكر و قدردانى مى شود.
روش هـاى مبتنى بر بثزوهش و حفظ كيفيـت آموزشهـا را در يكك مدت زمان طولانى للازم وضرورى مى دانند.

به طور كلى نتايج يثزوهش نشـان مىدهد با وجود فعاليتهاى بسـيار زيادى كه درباره توسعه حرفهاى معلمان و آموزش دانش آموزان با اختلال طيف اوتيسـم انجام شــده اسـت، سـاختار برنامههاى توسـعه حرفهاى بر اساس نياز و امكانات، تطبيقى بوده و با توجه به اينكه آموزش مهارتهاى تحصــيلى وكاهش آســيبهاى رفتارى در كلاس درس از اولويتهاى

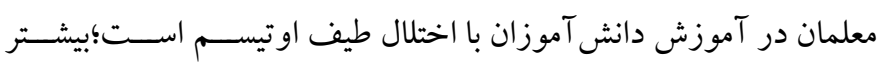
مطـالعـات، مـداخلـات و راهبردهـاى رفتـارى را آموزش دادهاند و تلاش كردهاند از مؤثرترين روش آموزش يعنى آموزش انفرادى و تركيبى بهره بَحيرند. در يزٔوهش حاضسر عدم بررسى محتواى آموزش داده شـده، مسـايل

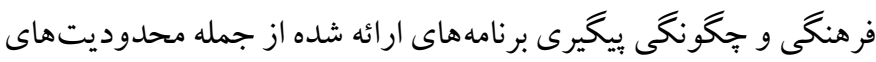
بررسـى مطالعه، و عدم دســترسـى به برخى مقالات از محدوديتهاى روش شـناسى در اين مرور نظاممند بودند. با توجه به محدوديت يزوهش حاضر، بيشنهاد مىشود محتو اى برنامههاى توسعه حرفهاى در اين زمينه و تأثير طولانى مدت اين برنامهها بر توانمندى معلمان و دانش آموزان مورد

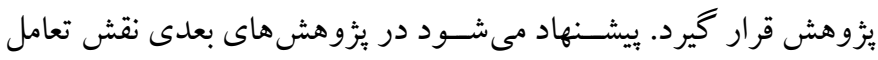




\section{References}

1. Hamadneh S, Alazzam M, Kassab M, Barahmeh S. Evaluation of intervention programs for children with autism. Int J Contemp Pediatrics. 2019; 7(4): 9341-7. [Link]

2. Ary SL. Parents' perception of a school-based inclusion program for their children with autism. [Doctoral's thesis]. [Minnesota, USA]: College of Education, Walden University; 2017, pp: 38-39.[Link]

3. Centers for Disease Control [CDC]. Autism disorder: Data and statistics.2016. Retrieved from http://www .cdc.gov/ncbddd/autism/data.html. [Link]

4. Samadi SA, Mahmoodizadeh A, McConkey R. A national study of the prevalence of autism among fiveyear-old children in Iran. Autism. 2012; 16(1): 5-14. [Link]

5. Bradley RJ. "Why single me out"? Peer mentoring, autism and inclusion in mainstream schools. [Doctoral's thesis]. [Birmingham, UK]: School of Education, University of Birmingham: 2017, pp: 1819. [Link]

6.Sigmon M, Tackett M, Azano A. Using children's picture books about autism as resources in inclusive classrooms. Read Teach. 2016; 70(1): 111-117. [Link]

7. Majoko T. Inclusion of children with autism spectrum disorders: Listening and hearing to voices from the grassroots. Rev J Autism Dev Disord. 2016; 46(4): 1429-1440.[Link]

8. Humphrey N. Including pupils with autistic spectrum disorders in mainstream schools. Support for learning, 2008; 23(1), 41-47. [Link]

9. Brock M, Huber H, Carter E, Juarez P, Warren Z. Statewide assessment of professional development needs related to educating students with autism spectrum disorder. 2014; 29(2): 67-79. [Link]

10.Barnhill G, Sumutka B, Polloway E, Lee E. Personnel preparation practices in ASD: A follow-up analysis of contemporary practices. Focus Autism Other Dev Disabl.2014; 29(1): 39-49. [Link]

11. Barnhill P, Polloway E, Sumutka B. A survey of personnel preparation practices in autism spectrum disorders. Focus Autism Other Dev Disabl. 2011; 26(2): 75-86. [Link]

12.Guldberg K, Parsons S, MacLeod A, Jones G, Prunty A, Balfe T. Implications for practice from 'International review of the evidence on best practice in educational provision for children on the autism spectrum'. Eur J Spec Needs Educ.2011; 26(1): 65-70. [Link]
13. Taylor J, Seltzer M. Employment and post-secondary educational activities for young adults with autism spectrum disorders during the transition to adulthood. Rev J Autism Dev Disord. 2011; 41(5): 566-574. [Link]

14. Cook B, Cook, S. Unraveling evidence-based practices in special education. J Spec Educ. 2013; 47(2): 71-82. [Link]

15. Hill D, Hill S. Autism Spectrum Disorder, Individuals with Disabilities Education Act, and Case Law: Who Really Wins? Preventing School Failure: Alternative Education for Children and Youth.2012; 56(3): 157164. [Link]

16. Zirkel P. Autism litigation under the IDEA: A new meaning of "disproportionality?" J Spec Educ.2011; 24: 92-103.[Link]

17. Alexander J, Ayres K, Smith K. A. Training teachers in evidence-based practice for individuals with autism spectrum disorder: A review of the literature. Teach Educ Spec Educ.2015; 38(1): 13-27. [Link]

18. Brock M, Carter E. Effects of a professional development package to prepare special education paraprofessionals to implement evidence-based practice. J Spec Educ.2015; 49(1): 39-51. [Link]

19. Buysse V, Rous B, Winton P. What Do We Mean by Professional Development in the Early Childhood Field? National Professional Development Center on Inclusion.2008; 11: 3-4. [Link]

20. Shyman E. Toward a globally sensitive definition of inclusive education based in social justice. Intl $\mathbf{J}$ Disabil Dev Educ.2015; 62(4): 351-362. [Link]

21. Cook B, Shepherd, Cook, Cook, L. Facilitating the effective implementation of evidence-based practices through teacher-parent collaboration. Teach Excep Child.2012; 44(3): 22-30. [Link]

22.Simpson R, McKee M, Teeter D, Beytien A. Evidence-based methods for children and youth with autism spectrum disorders: Stakeholder issues and perspectives. Exceptionality.2007; 15(4): 203-217. [Link]

23. Cook B, Odom S. Evidence-based practices and implementation science in special education. Exceptional children.2013; 79(2): 135-144. [Link]

24. Paynter JM, Ferguson S, Fordyce K, Joosten A, Paku S, Stephens M, Keen D. Utilisation of evidence-based practices by ASD early intervention service providers. Autism, 2017; 21: 167-180. [Link]

25. Webster A, Cumming J, Rowland S. Empowering Parents of Children with Autism Spectrum Disorder. Springer Singapore; 2017; 27-52. [Link] 
26. Klebanoff S. School Psychologists' and Counselors' Perspectives on Evidence-Based Practices for Children with Autism Spectrum Disorders [Doctoral's thesis]. [California, USA]: Philosophy in Education, University of California: 2018, pp: 34. [Link]

27. Sam AM, Cox AW, Savage MN, Waters V, OdomSL. Disseminating Information on Evidence-Based Practices for Children and Youth with Autism Spectrum Disorder: AFIRM. J Autism Dev Disord. 2019; 24(2): 1-10. [Link]

28. Odom S, Boyd B, Hall L, Hume K. Evaluation of comprehensive treatment models for individuals with autism spectrum disorders. J Autism Dev Disord. 2010; 40(4): 425-436. [Link]

29. Scheuermann B, Webber J, Boutot E, Goodwin M. Problems with personnel preparation in autism spectrum disorders. Focus Autism Other Dev Disabl. 2003; 18(3): 197-206. [Link]

30. Lang R, O'Reilly M, Sigafoos J, Machalicek W, Rispoli M, Shogren K, Hopkins S. Review of teacher involvement in the applied intervention research for children with autism spectrum disorders. Educ Train Autism Dev Disabil. 2010; 45(2): 268-283. [Link]

31.Machalicek W, O'Reilly M, Beretvas N, Sigafoos J, Lancioni G, Sorrells A, Rispoli M. A review of school-based instructional interventions for students with autism spectrum disorders. Res Autism Spectr Disord.2008; 2(3): 395-416. [Link]

32. Suhrheinrich J. Training teachers to use pivotal response training with children with autism: Coaching as a critical component. Teach Educ Spec Educ. 2011; 34(4): 339-349. [Link]

33. Bethune K, Wood C. Effects of coaching on teachers' use of function-based interventions for students with severe disabilities. Teach Educ Spec Educ.2013; 36(2): 97-114. [Link]

34.Morrier M, Hess K, Heflin L. Teacher training for implementation of teaching strategies for students with autism spectrum disorders. Teach Educ Spec Educ. 2011; 34(2): 119-132. [Link]

35. Simonsen B, Myers D, DeLuca C. Teaching teachers to use prompts, opportunities to respond, and specific praise. Teach Educ Spec Educ.2010; 33(4): 300-318. [Link]

36.Yoon K, Duncan T, Lee S, Scarloss B, Shapley K. Reviewing the evidence on how teacher professional development affects student achievement. Issues \& Answers. Regional Educational Laboratory Southwest. 2007; 033, pp: 12-14. [Link]

37.Pelletier K, McNamara B, Braga-Kenyon P, Ahearn $\mathrm{W}$. Effect of video self-monitoring on procedural integrity. Behavioral Interventions.2010; 25(4): 261274. [Link]

38. Odom, S. The tie that binds: Evidence-based practice, implementation science, and outcomes for children. Topics Early Child Spec Educ.2009; 29(1): 53-61. [Link]

39. Stahmer A, Collings N, Palinkas L. Early intervention practices for children with autism: Descriptions from community providers. Focus Autism Other Dev Disabl.2005; 20(2):66-79. [Link]

40. Hess K, Morrier, Heflin L, Ivey M. Autism treatment survey: Services received by children with autism spectrum disorders in public school classrooms. J Autism Dev Disord. 2008; 38(5): 961971. [Link]

41.Ledford J, Zimmerman K, Harbin E, Ward S. Improving the use of evidence-based instructional practices for paraprofessionals. Focus Autism Other Dev Disabl. 2018; 33(4): 206-216. [Link]

42.Artman-Meeker K, Fettig A, Barton E, Penney A, Zeng S. Applying an evidence-based framework to the early childhood coaching literature. Topics Early Child Spec Educ. 2015; 35(3): 183-196. [Link]

43. Casey A, McWilliam R. The characteristics and effectiveness of feedback interventions applied in early childhood settings. Topics Early Child Spec Educ. 2011; 31(2): 68-77. [Link]

44. Bitsika V, Warren A, Sharpley C. An Evaluation of a Professional Development Programme in Functional Behavior Assessment for Educators in Australia. Int $\mathbf{J}$ Spec Educ.2017; 32(2): 630-641. [Link]

45. Higgins J, Green S. Cochrane Handbook for Systematic Reviews of Interventions Version 5.3. The Cochrane Collaboration Website.2017. [Link]

46. Keen D, Sigafoos J, Woodyatt G. Replacing prelinguistic behaviors with functional communication. J Autism Child Schizophr. 2001; 31(4): 385-398. [Link]

47. Lerman, D. C., Vorndran, C. M., Addison, L., \& Kuhn, S. C. (2004). Preparing teachers in evidencebased practices for young children with autism. School Psych Rev, 33(4), 510-526. [Link]

48. Sarokoff R, Sturmey P. The effects of behavioral skills training on staff implementation of discrete-trial teaching. J Appl Behav Anal. 2004; 37(4): 535-538. [Link]

49.Ryan C, Hemmes N, Sturmey P, Jacobs J, Grommet E. Effects of a brief staff training procedure on instructors' use of incidental teaching and students' frequency of initiation toward instructors. Res Autism Spectr Disord. 2008; 2(1): 28-45. [Link] 
50. Leblanc L, Richardson W, Burns K. Autism spectrum disorder and the inclusive classroom effective training to enhance knowledge of ASD and evidence-based practices. Teach Educ Spec Educ. 2009; 32 (2): 166179. [Link]

51.Browder D, Jimenez B, Mims P, Knight V, Spooner F, Lee A, Flowers C. The effects of a "tell-show-tryapply" professional development package on teachers of students with severe developmental disabilities. Teach Educ Spec Educ. 2012; 35(3): 212227. [Link]

52. Garland K, Vasquez E, Pearl C. Efficacy of individualized clinical coaching in a virtual reality classroom for increasing teachers' fidelity of implementation of discrete trial teaching. Educ Train Autism Dev Disabil. 2012; 47(4): 502515.[Link]

53. Stahmer A, Rieth S, Lee E, Reisinger E, Mandell D, Connell J. Training teachers to use evidence-based practices for autism: Examining procedural implementation fidelity. Psychology in the Schools. 2015; 52(2): 181-195. [Link]

54. Bethune K. Effects of Coaching on Teachers' Implementation of Tier 1 School-Wide Positive Behavioral Interventions and Support Strategies. Journal of Positive Behavior Interventions. 2017; 19(3):131-142. [Link] 